\title{
Hormone-stimulated Cyclic AMP Production by Skin Fibroblasts Cultured from Healthy Persons and Patients with Cystic Fibrosis
}

\author{
PAMELA B. DAVIS, ${ }^{(27)}$ S. CAROLINE HILL, AND MARTA M. ULANE \\ Pediatric Metabolism Branch, National Institute of Arthritis, Metabolism, and Digestive Disease, National Institutes of \\ Health, Bethesda, Maryland, USA
}

\section{Summary}

The experiments reported here illustrate a few of the factors apart from genes which can influence hormone-responsive generation of cyclic adenosine $3^{\prime}: 5^{\prime}$-monophosphate in human fibroblasts. For both normal and cystic fibrosis fibroblasts, the isoproterenol stimulation ratio was maximal 2 to 3 days after subculture and declined thereafter; prostaglandin $\mathrm{E}_{1}$ stimulation ratio was maximal 7 to 10 days after subculture. Cells dislodged from the plate by either scraping or trypsinization had reduced isoproterenol or prostaglandin $\mathbf{E}_{1}$ stimulation ratios compared to cells studied in situ. Fibroblasts from healthy controls and cystic fibrosis patients plated simultaneously and grown in three different culture conditions responded similarly to the change in growth conditions. Addition to the incubation medium of polyamines, calcium, magnesium, or guanosine triphosphate did not alter the stimulation ratios for isoproterenol or prostaglandin $E_{1}$. Repeated measures analysis indicates that cellular content of cyclic adenosine $3^{\prime}: 5^{\prime}$ monophosphate is not a reliable measure for comparing cell lines; isoproterenol stimulation ratio is a reliable measure, but there is large variation from cell line to cell line. Isoproterenol stimulation ratio was the same for normal and cystic fibrosis fibroblasts in each of the three culture conditions tested at both three and ten days after subculture.

\section{Speculation}

Because of the unexplained day-to-day variability in cellular cyclic adenosine 3 ':5' $5^{\prime}$-monophosphate content, the multiple exogenous influences on hormone-responsive cyclic adenosine $3^{\prime}: 5^{\prime}$ monophosphate, and the potential limitations of studying fibroblasts only on their support so as not to perturb the membraneassociated receptor adenylate cyclase system, the cultured skin fibroblast may not be the optimal system for population studies of adrenergic-responsive adenylate cyclase in human disease.

The cultured skin fibroblast is an appealing model system for the study of genetic disease in man. Cultured fibroblasts are endowed with the abnormal genetic material yet are remote from the influences of drugs and illness to which the patient is subject, and the biochemical milieu of the fibroblast can be manipulated to a far greater extent than the intact human organism. Fibroblasts possess an adrenergic-responsive adenylate cyclase (EC 4.6.1.1) system $(16,20)$, and the direction of the adenylate cyclase response to isoproterenol in skin fibroblasts from normal and cystic fibrosis (CF) donors has been controversial in the literature. Buchwald (4) first reported that $\mathrm{CF}$ fibroblasts produced more cyclic adenosine $3: 5^{\prime}$-monophosphate (cAMP) in response to isoproterenol than normal fibroblasts. Subsequently, in a larger series of cell lines of lower passage number, this result could not be confirmed (5). Using different culture conditions, we found that the CF fibro- blasts were less responsive to isoproterenol stimulation than fibroblast lines established from normal individuals (8).

Fibroblasts from patients with CF have been especially resistant to reproducible demonstration of any type of abnormality. Although this may be because the abnormal gene is not expressed in the fibroblast, it may also be because of variations in culture and experimental conditions $(9,24)$. Technical factors can complicate the usefulness of the fibroblast as a model system. In this paper, we report the effects of different culture conditions, time in culture, composition of incubation medium, methods of processing cells, and methods of data analysis on the cAMP response to isoproterenol in fibroblasts grown from biopsies of normal and CF skin.

\section{MATERIALS AND METHODS}

\section{MATERIALS}

Isoproterenol, polyamines, GTP and theophylline were purchased from Sigma Chemical, St. Louis, MO. Prostaglandin $E_{1}$ $\left(\mathrm{PGE}_{1}\right)$ was a gift of Dr. John Pike, The Upjohn Co., Kalamazoo, MI. Trypsin $(0.25 \%)$ was purchased from Grand Island Biological Co., Grand Island, NY. Dulbecco's phosphate-buffered saline without calcium or magnesium (PBS) (10) and $\alpha$ medium (22) were obtained from the NIH media unit. Eagle's minimal essential medium with Earles' salts (11) (MEM-E), fetal bovine serum, neomycin sulfate, glutamine, and nonessential amino acids (NEAA) (11) were purchased from Associated Biomedic Systems, Inc., Bethesda, MD.

Growth medium (GM) contained MEM-E, glutamine (292 mg/ liter, NEAA, neomycin $(50 \mu \mathrm{g} / \mathrm{ml})$, and fetal bovine serum (10\%).

\section{CELL CULTURE}

Human use committees approved procedures for obtaining skin biopsies, and all donors granted informed consent. Healthy persons without family history of pulmonary or gastrointestinal disease, ages 18 to 23 , and patients with $\mathrm{CF}$, ages 16 to 23 , underwent 3- to 4-mm punch biopsies of the skin of the forearm or hip. Biopsies were minced finely with scissors, incubated at $37^{\circ} \mathrm{C}$ in GM in bottles flushed with $\mathrm{CO}_{2}$ and sealed, and fed every 3 days. Monolayers of fibroblasts were ready in one month and were subultured once prior to storage and frozen in liquid $\mathrm{N}_{2}$ in GM with $8 \%$ dimethyl sulfoxide. Ampules were rapidly thawed when desired, grown to confluence, subcultured by trypsinization $(0.25 \%$ for $<5 \mathrm{~min}$ ), and fed every 3 to 4 days. Cells were periodically tested for the presence of Mycoplasma.

For condition A, the cells were grown in GM without NEAA in closed lucite boxes flushed with $\mathrm{CO}_{2}$. For condition $\mathrm{B}$, cells were grown in $\mathrm{GM}$ in an atmosphere of $5 \% \mathrm{CO}_{2}-95 \%$ air. For condition $\mathrm{C}$, the conditions described by Buchwald. (4) were duplicated ( $\alpha$ medium-15\% FBS) except that neomycin $(50 \mu \mathrm{g} / \mathrm{ml})$ was added. 
Cells were studied prior to passage 9 , except for a few internally controlled experiments in which fibroblasts up to passage 16 were used. Cell lines were always studied in pairs, one normal and one CF cell line.

\section{MEASUREMENT OF CAMP}

All experiments were performed on triplicate samples of cells, and these were assayed in duplicate for cAMP by the competitive protein binding technique of Brown et al. (2). Net isoproterenolstimulated cAMP was calculated by subtracting cAMP generated in the absence of isoproterenol (basal cAMP) from cAMP generated in the presence of isoproterenol. The isoproterenol stimulation ratio is the ratio of cAMP generated in the presence of isoproterenol to basal cAMP.

\section{METHODS OF PROCESSING}

Fibroblasts were grown in condition $\mathrm{A}$ and harvested 3 days after plating by one of the three methods described below.

\section{IN SITU METHOD}

The procedure of Gilman and Minna (14) was used with minor modifications. Fibroblasts $\left(1.7 \times 10^{5}\right.$ cells plated) were grown in microtiter wells (Costar 3506, $35 \mathrm{~mm}$ diameter) and washed three times with PBS. They were then incubated with PBS-10 mM theophylline for $15 \mathrm{~min}$ at $37^{\circ} \mathrm{C}$. Agonists were added, and incubation was continued; then $1 / 10$ volume $50 \%$ trichloroacetic acid (TCA) was added (or, alternatively, the PBS was aspirated and replaced with 5\% TCA). TCA was extracted three times with 5 volumes of water-saturated ether, and the aqueous phase was lyophilized and assayed for cAMP. Recovery of exogenous $\left[{ }^{3} \mathrm{H}\right]$ cAMP added to the TCA was 92 to $98 \%$.

\section{SCRAPED CELLS}

The method of Tallman et al. (23) was used with minor modifications. Fibroblasts grown in Petri plates were washed three times and scraped gently into PBS with a rubber policeman. Cells were $>95 \%$ viable by trypan blue exclusion. After separation by centrifugation $(400 \times g, 10 \mathrm{~min})$, cells were washed three times with PBS and then incubated in PBS-10 mM theophylline for 15 min at $37^{\circ} \mathrm{C}$. Agonists were then added, and incubation continued for $15 \mathrm{~min}$. Accumulation of cAMP was terminated by boiling for $2 \mathrm{~min}$, and samples were assayed directly for cAMP. Recovery of $\left[{ }^{3} \mathrm{H}\right]$ cAMP added before boiling was $>98 \%$.

\section{TRYPSINIZATION METHOD}

Fibroblasts grown in plastic or glass bottles were washed three times with PBS, and then exposed to trypsin $(0.25 \%)$ for the minimum time required to dislodge the cells from the support (always $<5 \mathrm{~min}$ ). Reaction was terminated by the addition of four volumes GM. Cells were separated by centrifugation $(400 \times g ; 10$ min) and washed three times with PBS. Cells were $>95 \%$ viable by trypan blue exclusion. Cells were incubated for $15 \mathrm{~min}$ at $37^{\circ} \mathrm{C}$ in PBS-10 mM theophylline, agonists were added and incubation continued for $15 \mathrm{~min}$. Accumulation of cAMP was terminated by boiling for $2 \mathrm{~min}$, and samples were assayed directly for cAMP. Recovery of exogenous $\left[{ }^{3} \mathrm{H}\right] \mathrm{cAMP}$ added before boiling was $>98 \%$.

\section{RESULTS AND DISCUSSION}

Studies utilizing cell cloning and hybridization have shown that the genotype of cultured cells affects the phenotypic response of cAMP to $\beta$-adrenergic stimulation $(3,14)$. The experiments reported here illustrate a few of the factors apart from genes which can influence hormone-responsive generation of cAMP in human fibroblasts. In most instances, they operated to a similar extent in fibroblasts derived from normal subjects and from CF patients.

\section{METHODS OF HARVESTING}

The method of preparing cells for study had a significant effect on measured cAMP content and hormone responsiveness. A receptor-enzyme system located in the plasma membrane might be perturbed by treatments, chemical or mechanical, which are sufficient to interrupt the membrane's connection to the support, and major morphologic alterations have been observed in human fibroblasts following both scraping and trypsinization (18). Thus an in situ method of studying the $\beta$-adrenergic responsive adenylate cyclase system would be preferred. However, because we anticipated future experiments requiring dislodged cells, such as measurements of adenylate cyclase activity in broken cell preparations, we conducted experiments comparing an in situ method with scraping and trypsinization for six normal and six CF cell lines grown in condition A. Trypsinization produced significant increases in basal levels of cAMP (Table 1), consonant with reports that trypsin activates adenylate cyclase in other cultured cell systems (15). However, trypsinized cells also showed significantly lower stimulation ratio for isoproterenol and $\mathrm{PGE}_{1}$ (Table 2 ), suggesting that the response of adenylate cyclase to receptormediated stimulation is altered. Cells scraped from the plates had basal levels of cAMP comparable to those measured in situ, but the $\mathrm{PGE}_{1}$ stimulation ratio was significantly reduced. The chemical basis of this interference with the hormone responsiveness of adenylate cyclase is unclear. However, studies with cultured fibroblasts dislodged from the plate, such as assay of adenylate cyclase in broken cell preparations or use of dislodged cells for binding studies of receptors must be interpreted with caution.

\section{GROWTH OF FIBROBLASTS RELATED TO CHANGES IN HORMONE-} STIMULATED cAMP

Cellular cAMP content varies with the cell cycle: human fibroblasts in the logarithmic phase have higher cAMP content than confluent cells (16), although in other cultured cells the pattern is reversed (6). Thus, if fibroblasts from normal persons and CF patients grew at different rates, differences in cellular cAMP content might result. In our studies, population doubling time was the same in normal and CF fibroblast lines, as reported previously from this laboratory (13). Cell number increased for about 5 days after subculture in all conditions tested and then remained stable; doubling time ( 24 to $36 \mathrm{hr}$ ) was the same in all conditions tested. Also, hormone-responsiveness of cAMP content has been shown to vary with time after subculture $(16,20)$. In these experiments (Fig. 1), the isoproterenol stimulation ratio was maximal 2 to 3 days and the $\mathrm{PGE}_{1}$ stimulation ratio was maximal 7 to 10 days after subculture for fibroblasts derived from both normal subjects and CF patients. This pattern of hormone responsiveness is characteristic of young fibroblasts $(16,20)$. (These cells had passage number of less than 9.) Both growth parameters and changes in basal cAMP and hormone responsiveness with time after subculture were similar in normal and CF fibroblast lines.

Table 1. Intracellular basal cAMP content of skin fibroblasts (pmoles $/ 10^{6}$ cells)

\begin{tabular}{cccc}
\hline & \multicolumn{3}{c}{ Method of harvest $^{1}$} \\
\cline { 2 - 4 } Cell type & In situ method & Scraped & Trypsinized \\
\hline $\begin{array}{c}\text { Normal } \\
(n=6)\end{array}$ & $27 \pm 22^{2}$ & $23 \pm 23$ & $43 \pm 26^{3}$ \\
CF $(n=6)$ & $13 \pm 8$ & $12 \pm 7$ & $60 \pm 28^{3}$ \\
\hline
\end{tabular}

${ }^{1}$ Fibroblasts were grown in condition $\mathrm{A}$ and studied 3 days after subculture by indicated methods as described in the text.

${ }^{2}$ Mean \pm S.D.

${ }^{3} P<0.05$ different from in situ method or scraped method (unpaired, two-tailed $t$ test). 
CHARACTER OF ISOPROTERENOL AND PGE 1 RESPONSE

The order of potency of agonists (Fig. 2) and the inhibition of esponse by propranolol but not phentolamine identified the atecholamine-responsive cAMP-generating system of human skin broblasts as a $\beta$-adrenergic system (17). Time courses of response or isoproterenol and $\mathrm{PGE}_{1}$ (Fig. 3) and dose-response relation or isoproterenol (Fig. 4) and for $\mathrm{PGE}_{1}$ (Fig. 5), a nonadrenergic timulator of adenylate cyclase, were similar in normal and CF amples. Figures 2 to 5 illustrate the data from one representative ormal and one CF cell line. Similar results were obtained in at east two additional normal and two other CF cell lines for the $\mathrm{GE}_{1}$ results and for at least three other normal and three other F cell lines for the isoproterenol results. Although the absolute alues of cAMP content varied considerably, the time course of esponse, dose-response relation and order of potency of agonists as quite consistent. On the basis of these data, the standard cubation conditions chosen for the remainder of the experiments vere with $10^{-5} \mathrm{M}$ isoproterenol or $10^{-6} \mathrm{M} \mathrm{PGE}_{1}$ for $15 \mathrm{~min}$.

\section{CULTURE CONDITIONS}

Culture conditions (the media and atmosphere in which the ells were grown) affected the cAMP response to isoproterenol. our normal and four CF fibroblast lines were studied by the in itu method at passage number less than 9. Cells from each line rere plated simultaneously in the three culture conditions decribed above (A, B, or C), and they were processed and assayed ggether at 3 and 10 days after subculture. Fibroblasts grown nder the conditions studied by Buchwald and Mapleson $(4,5)$, ondition $\mathrm{C}$, had somewhat $(0.05<P<0.1)$ increased cAMP esponse to isoproterenol at 3 days after subculture but signifiantly $(P<0.05)$ diminished response at 10 days after plating ompared to cells grown in condition A or B (Fig. 6). Inasmuch $\mathrm{s}$ the compositon of $\alpha$ medium is quite different from that of GEM-E, it is impossible to implicate specific components in the ifferent responses. These differences in culture conditions might ause differences in the growth fraction of the cultures, and the hanges in isoproterenol responsiveness might reflect growth ather than nutritional differences. However, nutrients such as utyrate affect numbers of $\beta$ receptors (22), and excess serine or thanolamine can result in increase in measured adenylate cyclase ctivity (19). In the present study, changes in culture conditions roduced parallel changes in the response to isoproterenol of ormal and CF fibroblasts.

\section{INCUBATION MEDIUM}

The standard medium was PBS with $10 \mathrm{mM}$ theophylline. The ffect of changes in this medium was studied in cells grown in

Table 2. Stimulation ratios for isoproterenol and $P G E_{1}$ for cultured skin fibroblasts

\begin{tabular}{lll}
\multicolumn{1}{c}{ Method of harvest ${ }^{1}$} & Normal $(n=6)$ & CF $(n=6)$ \\
soproterenol $\left(10^{-5} \mathrm{M} ; 15 \mathrm{~min}\right)$ & & \\
& & \\
$\quad$ In situ method & $9.6 \pm 6.1^{2}$ & $5.0 \pm 2.3^{3}$ \\
Scraped & $6.3 \pm 7.6$ & $3.9 \pm 3.8$ \\
Trypsinized & $3.5 \pm 2.0$ & $2.7 \pm 1.1^{4}$
\end{tabular}

$\mathrm{PGE}_{1}\left(10^{-6} \mathrm{M} ; 15 \mathrm{~min}\right)$

$\begin{array}{lcc}\text { In } \text { situ method } & 25 \pm 11 & 33 \pm 17 \\ \text { Scraped } & 4.5 \pm 5.4^{4} & 6.9 \pm 6.7^{4} \\ \text { Trypsinized } & 8.5 \pm 4.4^{4} & 7.7 \pm 5.9^{4}\end{array}$

${ }^{1}$ Fibroblasts were grown in condition $\mathrm{A}$ and studied 3 days after ubculture by methods described in the text.

${ }^{2}$ Mean \pm S.D.

${ }^{3} P<0.05$ different from normal (unpaired, two-tailed $t$ test).

${ }^{4} P<0.05$ different from in situ method (unpaired, two-tailed $t$ test).
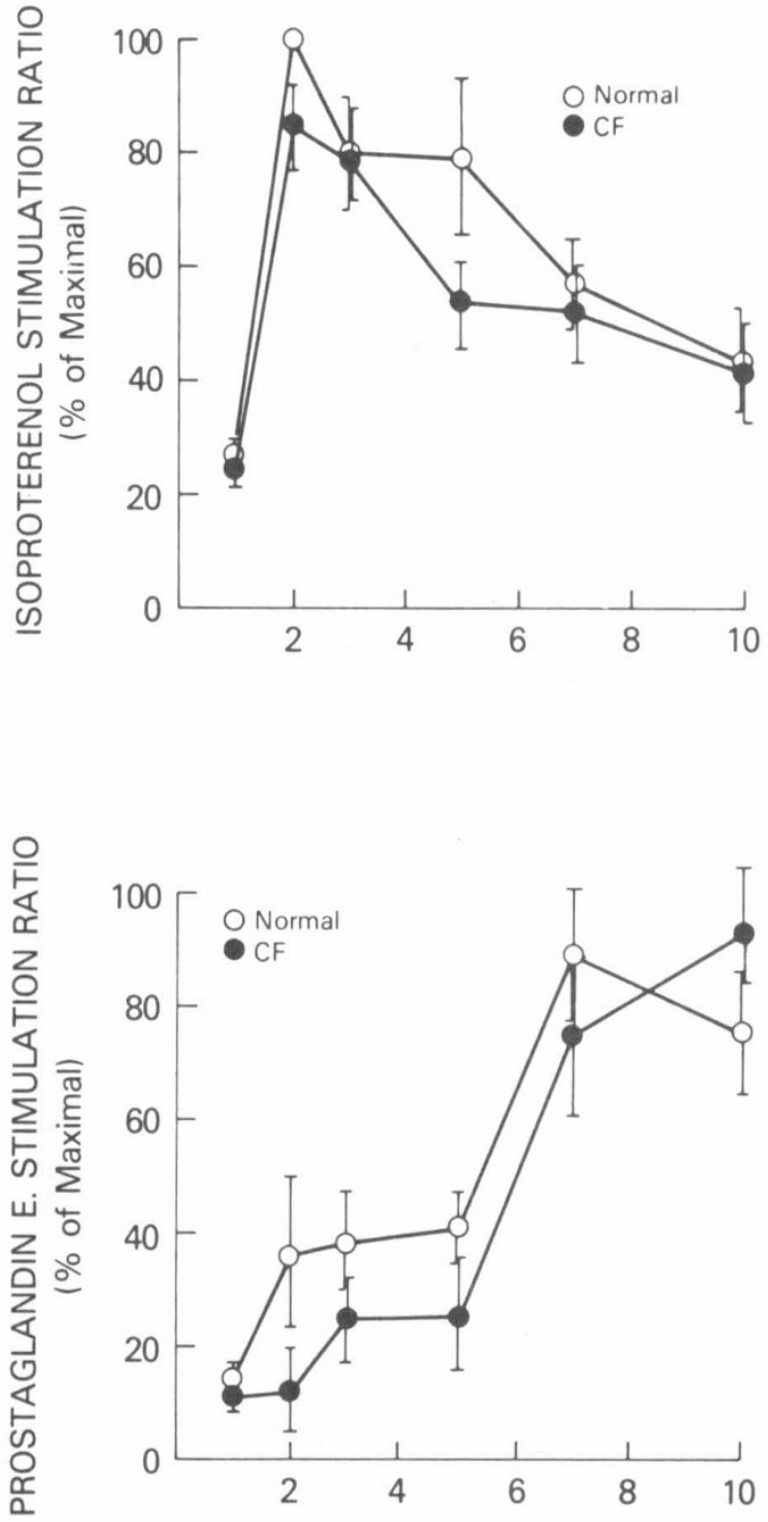

DAYS AFTER SUBCULTURE

Fig. 1. Change in stimulation ratio for isoproterenol (top) and $\mathrm{PGE}_{1}$ (bottom) with time after subculture for three normal and three CF fibroblast cell lines. Cells were grown in condition B and processed by the in situ method. The maximum stimulation ratio was designated $100 \%$, and other ratios were expressed as a fraction of it. Points, mean \pm S.D.

condition B 3 days after subculture. Each agent was studied in at least 2 normal and $2 \mathrm{CF}$ cell lines. Additions to the medium were made prior to preincubation for $15 \mathrm{~min}$ at $37^{\circ} \mathrm{C}$ and remained in the medium during stimulation with isoproterenol of $\mathrm{PGE}_{1}$. Addition of GTP (1 mM) or polyamines (spermine, spermidine, or putrescine, (1 mM) had no effect on basal, isoproterenol-stimulated, or $\mathrm{PGE}_{1}$-stimulated cAMP levels, consistent with other reports which show no influence of these agents on whole cell preparations, but substantial effects in broken cell preparations $(21,25)$. Calcium (in concentrations ranging from $10^{-6}$ to $2 \times 10^{-3}$ $\mathrm{M}$ ) and magnesium (in concentrations of $10^{-4}$ to $2.5 \times 10^{-2} \mathrm{M}$ ) did not affect the isoproterenol stimulation ratio. Table 3 shows the changes in cAMP content produced by the presence of magnesium $(1 \mathrm{mM})$ and calcium $(1 \mathrm{mM})$ in the incubation medium. Substituion of MEM-E for PBS gave variable results for the cAMP content of the fibroblasts but did not alter the stimulation ratio for isoproterenol or $\mathrm{PGE}_{1}$. Substitution of isobutylmethylxanthine $(1 \mathrm{mM})$ for theophylline $(10 \mathrm{mM})$ resulted in about $25 \%$ increase 


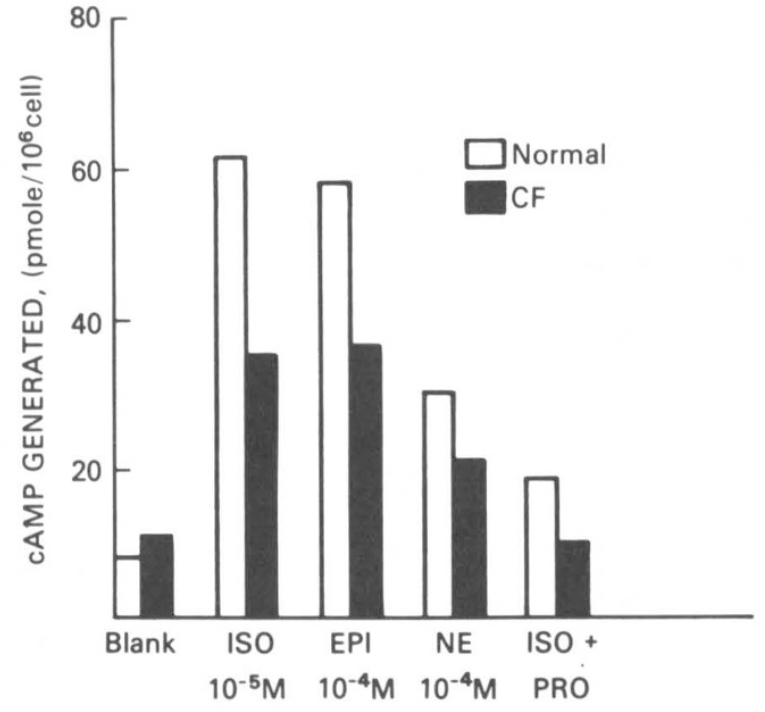

Fig. 2. Response of cAMP to adrenergic agonists and antagonists after preincubation with $10 \mathrm{mM}$ theophylline (Blank) and exposure to agonists for $15 \mathrm{~min}$ at $37^{\circ} \mathrm{C}$. ISO, isoproterenol; $E P I$, epinephrine; $N E$, norepinephrine; $I S O+P R O$, isoproterenol $\left(10^{-5} \mathrm{M}\right)$ plus propranolol $\left(10^{-5} \mathrm{M}\right)$.

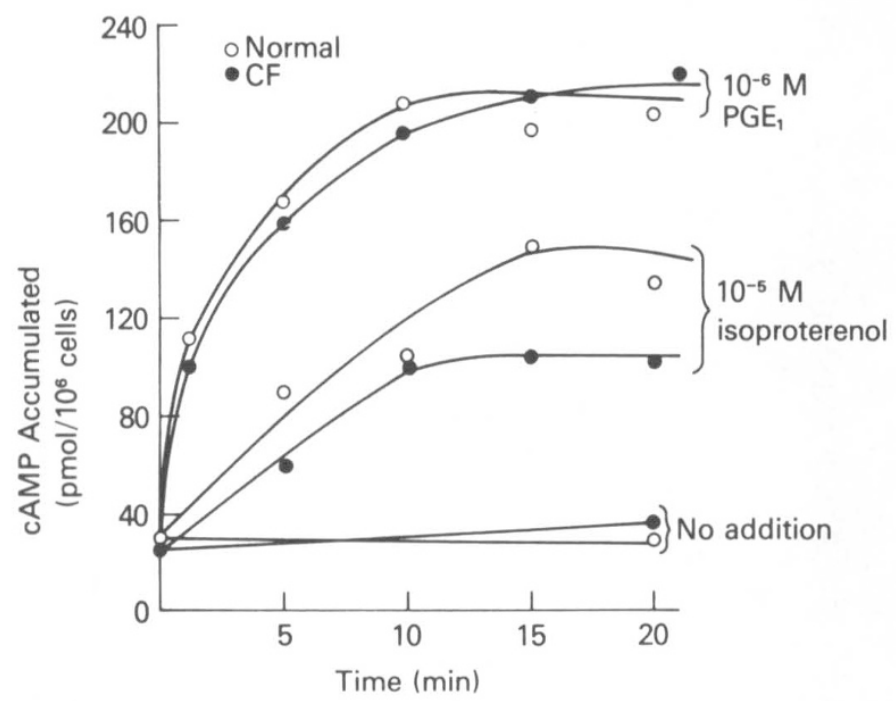

Fig. 3. Response of a representative normal and CF cell line to isoproterenol $\left(10^{-5} \mathrm{M}\right)$ and $\mathrm{PGE}_{1}\left(10^{-6}\right)$. Fibroblasts were grown in condition $\mathrm{A}$ for 3 days, preincubated $15 \mathrm{~min}$ with PBS containing $10 \mathrm{mM}$ theophylline, exposed to agonists for the indicated time, and processed by the in situ method.

in the absolute values for cAMP with or without agonists, but no change in the stimulation ratios.

\section{RELIABILITY OF RESULTS}

We studied two normal and two CF fibroblast lines grown in condition A on four separate occasions each, and Buchwald and Mapleson (5) reported data for a total of eight cell lines each studied twice. To test the reliability of the various ways of reporting the results for isoproterenol-stimulated cAMP, we used this repeated measure data to generate intraclass correlation coefficients according to the method of Bartko and Carpenter (1). This method tests the reliability of data by comparing the withinsubject variability on repeated measures to the between-subject variability. From Table 4, it is clear that the isoproterenol stimulation ratio is the only reliable measure. Isoproterenol-stimulated cAMP, whether determined in Buchwald's laboratory or our own, is not reliable. Even though the stimulation ratio is a reliable measure, there was a large variation from cell line to cell line with coefficient of variation $68 \%$ for normal cell lines and $44 \%$ for the CF cell lines.

\section{DAY-TO-DAY VARIATION}

Thus, many factors other than the genetic endowment of the cells influenced the cAMP content of the cells and the isoproterenol stimulation ratio, but these influences were comparable in normal and CF cells. Analysis of these influences and of possible differences between normal and CF genotypes was complicated by substantial variation from day to day in the measured cAMP content of the fibroblasts. The reason for this is unclear. Triplicate samples studied on the same day (that is, three separate microtiter wells used for the same point) typically gave closely replicate values (within $5 \%$ of the mean), so the inherent variability of the assay is probably not at fault. Some of the potential factors, such as variation in the composition of the incubation medium or

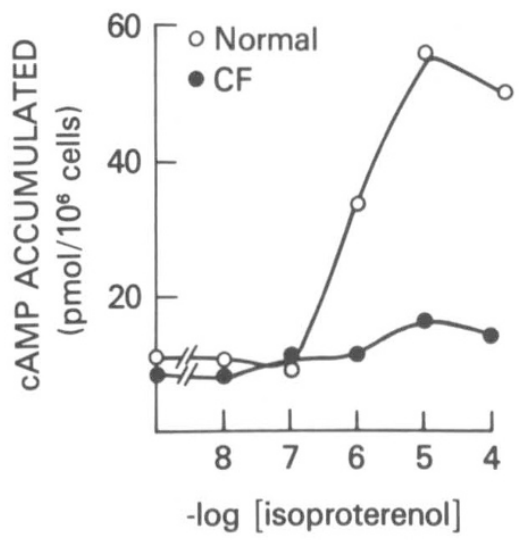

Fig. 4. Dose-response curve for isoproterenol for a representative nor mal and CF cell line. Fibroblasts were grown in condition A for 3 days preincubated for $15 \mathrm{~min}$ with PBS containing $10 \mathrm{mM}$ theophylline, incu bated with the indicated concentrations of isoproterenol for $15 \mathrm{~min}$, and processed by the in situ method.

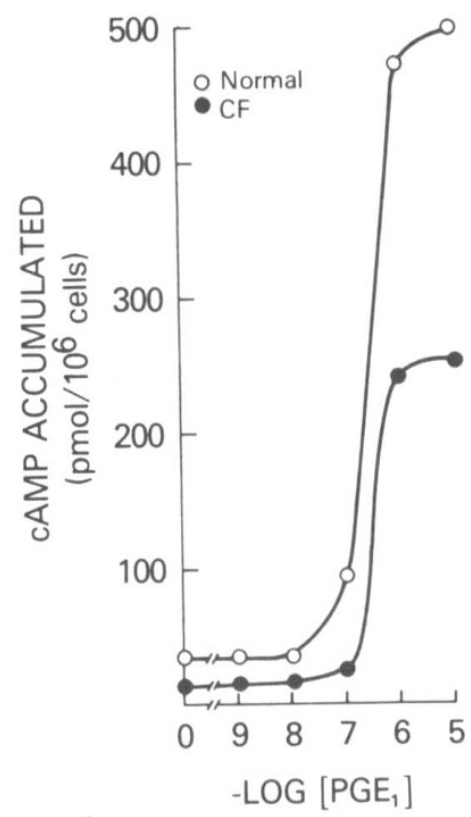

Fig. 5. Dose-response curve for $\mathrm{PGE}_{1}$ for a representative normal anc $\mathrm{CF}$ cell line. Fibroblasts were grown in condition A for 3 days, preincubated for $15 \mathrm{~min}$ with PBS containing $10 \mathrm{mM}$ theophylline, incubated with the indicated concentration of $\mathrm{PGE}_{1}$ for $15 \mathrm{~min}$, and processed by the in situ method. 


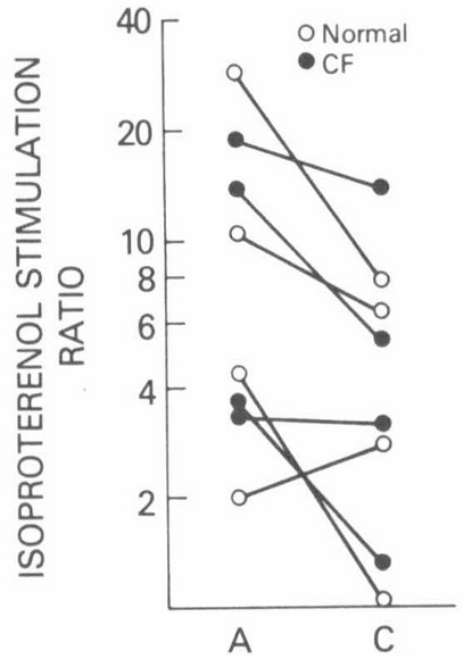

Fig. 6. Isoproterenol stimulation ratios at 10 days after subculture for our normal and four CF cell lines grown in two culture conditions (A and ). Lines connect points generated by the same cell line. Isoproterenol timulation ratio was significantly less in condition $\mathrm{C}(P<0.05$; paired $t$ est).

Table 3. Accumulation of cAMP in cultured skin fibroblasts ${ }^{1}$

$\begin{array}{lcc}\text { Addition to incubation medium } & \text { Normal } & \mathrm{CF} \\ \mathrm{Mg}^{2+}(\mathrm{lmM}) & & \\ & & \\ \text { Basal cAMP } & 123 \pm 19^{2}(8)^{3} & 113 \pm 27(8) \\ \text { Isoproterenol-stimulated } & 135 \pm 15(4)^{4} & 169 \pm 55(4)^{4} \\ \quad \text { cAMP } & & \\ \text { Stimulation ratio for isopro- } & 107 \pm 43(4) & 123 \pm 45(4)\end{array}$
terenol

$\mathrm{Ca}^{2+}(\operatorname{lmM})$

\section{Basal cAMP}

Isoproterenol-stimulated cAMP

Stimulation ratio for isoproterenol

${ }^{1}$ Results are expressed as percentage of values obtained with no addiions to incubation medium.

${ }^{2}$ Mean \pm S.D.

${ }^{3}$ Numbers in parentheses, number of trials.

${ }^{4}$ Significantly different from control (no addition to incubation metium), $P<0.05$, paired $t$ test.

Table 4. Analysis of reliability of methods of expressing data

\begin{tabular}{lcc}
\multicolumn{1}{c}{ Data expression } & $\begin{array}{c}\text { Intraclass correlation } \\
\text { coefficient (13) }\end{array}$ & $F$ \\
\hline Stimulation ratio & 0.76 & $16.6^{1}$ \\
Net isoproterenol-stimulated cAMP & 0.05 & 1.5 \\
Total isoproterenol-stimulated & 0.04 & 1.4 \\
cAMP & & \\
Total isoproterenol-stimulated & 0.01 & 0.3
\end{tabular}

cAMP [calculated from Buch-

wald's data (5)]

${ }^{1} P<0.05$.

rariation of cAMP recovery, have been checked by us and discarded. Variation of phosphodiesterase inhibition is possible, but inlikely because variability persisted whether theophylline, isooutylmethylxanthine, or Ro20-1724 was used as inhibitor. The mixed cell nature of the fibroblast culture may contribute to the variance. Examination of the data of Gilman and Minna (14) shows that cell lines cloned from the same culture (even by the same selective pressure) may have widely varying cAMP content and response to isoproterenol, so if different platings randomly contain more of one cell type than another, substantial differences in cAMP content and isoproterenol response may result. Also, some variance may be contributed by changes in the growth fraction. The metabolic status of the cells when they are trypsinized and subcultured, the degree of injury from trypsin to be repaired, and small time differences between subculture and testing could influence growth fraction, which in turn affects cAMP levels (Fig. 1). Synchronizing the cell culture might help to reduce the variance.

\section{COMPARISON OF NORMAL AND CF CELL LINES}

The stimulation of intracellular cAMP by isoproterenol has been shown to be reduced in both mononuclear cells and granulocytes from CF patients compared to leukocytes from healthy controls or those with other chronic and acute lung diseases (7). Similarly, in our initial studies, at 3 days postsubculture six CF cell lines had significantly lower net isoproterenol-stimulated cAMP and isoproterenol stimulation ratio compared to six normal cell lines (Table 2). Subsequent studies expanded this group to 10 normal and $10 \mathrm{CF}$ cell lines, and the difference between them was smaller and not statistically significant $(0.1>P>0.05)$. There were no statistically significant differences between normal and $\mathrm{CF}$ cell lines grown in conditions $\mathrm{B}$ or $\mathrm{C}$ at 3 days after subculture. At 10 days after subculture, isoproterenol stimulation ratios for normal and CF fibroblasts were the same in each culture condition. Normal and CF cell lines cannot be distinguished on the basis of isoproterenol-stimulated cAMP content. Review of the data from pairs of normal and CF cell lines studied simultaneously revealed no consistent relative response of cAMP to isoproterenol, and we found it impossible to identify the CF cells on this basis, even as paired samples.

Thus we find that intracellular cAMP content and response to $\beta$-adrenergic agents and $\mathrm{PGE}_{1}$ are comparable in normal and $\mathrm{CF}$ fibroblast lines. Moreover, exogenous influences on this system such as time in culture, methods of harvest, composition of culture medium, and composition of incubation medium have similar effects on normal and CF fibroblasts. Epstein et al. (12) have shown that phosphodiesterase activity and its response to theophylline or isoproterenol, cAMP binding, and cAMP-dependent protein kinase activity are comparable in normal and CF fibroblasts. Thus, a clear abnormality in cAMP metabolism had not been demonstrated in CF fibroblasts. However, CF fibroblasts are more resistant to toxic effects of isoproterenol, theophylline, and dibutyryl cAMP, leaving open the question of a lesion in the cAMP pathway distal to its interaction with protein kinase (12).

On the basis of the multiple exogenous influences on hormoneresponsive cAMP, the largely unexplained day-to-day variability in cellular cAMP content, and the potential limitations of studying the cultured cells only on their support so as not to perturb the membrane-associated hormone receptor-enzyme system, it seems that the cultured skin fibroblast may not be the optimal system for population studies of adrenergic-responsive adenylate cyclase in human disease.

\section{REFERENCES AND NOTES}

1. Bartko, J. J., and Carpenter, W. T.: On the methods and theory of reliability. J. Nerv. Ment. Dis., 163: 307 (1967).

2. Brown, B. L., Albano, J. D. M., Ekins, R. P., Sgherzi, A. H., and Tampion, W. A simple and sensitive saturation assay method for the measurement of adenosine 3:5 cyclic monophosphate. Biochem. J., 121: 561 (1971).

3. Brunton, L. L., Maguire, M. E., Anderson, H. J., and Gilman, A. G.: Expression of genes for metabolism of cyclic adenosine 3:5 monophosphate in somatic cells. J. Biol. Chem., 252: 1293 (1977).

4. Buchwald, M.: Abnormal levels of $3: 5$ cyclic AMP in isoproterenol-stimulated fibroblasts from patients with cystic fibrosis. Proc. Natl. Acad. Sci. U. S. A., 73: 2899 (1976).

5. Buchwald, M., and Mapleson, J. L.: Adenosine 3:5-cyclic AMP in fibroblasts 
from patients with cystic fibrosis and its relationship to secretion. Mod. Probl. Paediatr., 19: 165 (1977).

6. Chlapowski, F. J., Kelly, L. A., and Butcher, R. W.: Cyclic nucleotides in cultured cells. Adv. Cyclic Nucleotide Res., 6: 245 (1975).

7. Davis, P. B., Braunstein, M., and Jay, C.: Decreased adenosine 3:5 cyclic monophosphate response to isoproterenol in cystic fibrosis leukocytes. Pediatr. Res., 12: 703 (1978)

8. Davis, P. B., and Hill, S. C.: Decreased adenosine 3:5 cyclic monophosphate production in response to isoproterenol in cystic fibrosis fibroblasts. Am. Rev Respir. Dis., 117: 328 (1978).

9. di Sant'Agnese, P. A., and Davis, P. B.: Research in cystic fibrosis. N. Engl. J. Med., 295: 534 (1976).

10. Dulbecco, R., and Vogt, M.: Plaque formation and isolation of pure lines with poliomyelitis viruses. J. Exp. Med., 99: 167 (1954).

11. Eagle, H:: Amino acid metabolism in mammalian cell cultures. Science (Wash D. C.), 130: 432 (1959)

12. Epstein, J., Breslow, J. L., Fitzsimmons, M. J., and Vayo, M. M.: Pleiotropic drug resistance in cystic fibrosis fibroblasts: increased resistance to cyclic AMP. Somatic Cell Genet., 4: 451 (1978).

13. Farrell, P. M., Pallavicini, J. C., and Ulane, M. M.: Growth characteristics and protein content of tissue-cultured fibroblasts from cystic fibrosis patients. Proc. Soc. Exp. Biol. Med., 149: 340 (1975).

14. Gilman, A. G., and Minna, J. D.: Expression of genes for metabolism of cyclic adenosine 3:5 monophosphate in somatic cells. I. Responses to catecholamines in parental and hybrid cells. J. Biol. Chem., 248: 6610 (1973).

15. Guiraud-Simplot, A., and Colobert, L.: Adenylate cyclase activation by trypsin in KB cell cultures. Experientia, 33: 899 (1977)

6. Haslam, R. J., and Goldstein, S.: Adenosine 3:5-cyclic monophosphate and senescent human fibroblasts during growth and stationary phase in vitro. Biochem. J., 144: 253 (1974).
17. Lefkowitz, R. J.: $\beta$-adrenergic receptors: recognition and regulation. N. Engl. J Med., 295: 323 (1976)

18. Lucky, A. W., Mahoney, M. J., Barnett, R. J., and Rosenberg, L. E.: Electror microscopy of human skin fibroblasts in situ during growth in culture. Exp Cell. Res. 92: 383 (1975)

19. Malkiewicz-Wasowicz, B., Gamst, O., and Stromme, J. H.: The influence of changes in the phospholipid pattern of intact fibroblasts on the activities o four membrane-bound enzymes. Biochim. Biophys. Acta, 482: 358 (1977).

20. Manganiello, V. C., and Breslow, J.: Effects of prostaglandin $E_{1}$ and isoprotereno on cyclic AMP content of human skin fibroblasts modified by time and cel density in subculture. Biochem. Biophys. Acta, 362: 509 (1974).

21. Schramm, M.: The cathecholamine-responsive adenlyate cyclase system and it: modification by 5 guanylylimido diphosphate. Adv. Cyclic Nucleotide Res., 5 105 (1975).

22. Stanners, C. P., Eliceri, G. L., and Green, H.: Two types of ribosome in mouse hamster hybrid cells. Nat. New Biol., 230: 52 (1954).

23. Tallman, J. F., Smith, C. C., and Henneberry, R. C.: Induction of functional $\beta$ adrenergic receptors in HeLa cells. Proc. Natl. Acad. Sci. U. S. A., 74: 873 (1977).

24. Tissue Culture Approaches to the Study of Cystic Fibrosis. Cystic Fibrosis Conference Reports, 2: 1 (1978).

25. Wolff, J., and Cook, G. H.: Simulation of hormone effects by polycations Endocrinology, 101: 1767 (1977).

26. The authors thank Dr. Paul A. di Sant'Agnese for advice and support, Caroline Jay for technical assistance, and Pat Biggar for preparing the manuscript.

27. Requests for reprints should be addressed to: Dr. P. B. Davis, Division o Pulmonary Medicine, University of Tennessee, College of Medicine, 951 Cour St., Memphis, TN 38163 (USA).

28. Received for publication April 16, 1979.

29. Accepted for publication October 22, 1979 